\title{
First episode of preschool wheeze requiring hospitalization: a prospective study on the chance of recurrence and associated factors
}

\author{
Karaked Chantawarangul, Jitladda Deerojanawong, Suchada Sritippayawan
}

\begin{abstract}
Background: Although wheezing is very common in preschoolers, epidemiologic studies in Thailand are quite limited. The likelihood of having a second wheezing episode following the first attack remains unclearly established.

Objectives: This study aims to investigate the incidence of recurrent wheezing in preschool children presenting with first wheezing episode and identify the associated factors.

Methods: The study is an observational prospective study conducted at the inpatient pediatric department. Patients admitted with first episode of wheezing were followed up as an outpatient approximately one week after hospital discharge and subsequently followed up by telephone 3-monthly with a structured questionnaire seeking information concerning recurrent wheezing, defined as having a second wheezing episode requiring bronchodilator within a 1-year period.
\end{abstract}

Results: The total of 97 patients, aged 6 months to 5 years, were recruited from June 2014 to November 2015. Thirty-five patients were excluded because of inaccessibility for telephone follow-up. Amongst the remaining 62 patients, twenty-eight (45.2\%) had recurrent wheezing within one year. The mean lapse duration was $4.7 \pm 3.7$ months after the first episode. Having an allergic sensitization to aeroallergen was a risk factor for recurrent wheezing (OR 2.48, 95\%CI 1.81-3.4). Although not statistically significant, having an allergic sensitization to food seems to be another related factor (OR 2.36, 95\%CI 1.75-3.18).

Conclusion: The recurrent rate of wheezing was 45\%, which was considerably significant. Allergic sensitization to aeroallergen might increase the risk. These patients should be followed up, especially within the first year after their first wheezing episode.

Keywords: First wheezing, Preschool, Hospitalized, Recurrent, Incidence, Associated factors

\section{Abbreviations:}

EVW, episodic viral wheeze; ER, emergency room; HFNC, high flow nasal cannula; mAPI, modified asthma predictive index;

MTW, multiple-trigger wheeze; OPD, outpatient department;

PIS, pulmonary index score; RSV, respiratory syncytial virus

\section{Introduction}

Wheezing is very common in infants and young children due to age specific anatomical and physiological properties. One in three children under the age of 3 years have at least one episode of wheezing prior to their third birthday, ${ }^{1}$ with a cumulative prevalence of up to $40 \%$ during the first 6 years of life. $^{2}$

Various phenotypes of recurrent wheezing have been recognized. It could be classified as transient, late onset, and persistent wheezing according to population based cohort
From:

Department of Pediatrics, Faculty of Medicine, Chulalongkorn University, Bangkok, Thailand 10330

Corresponding author:

Karaked Chantawarangul

Department of Pediatrics, Faculty of Medicine, Chulalongkorn University

1873 Rama IV road, Patumwan, Bangkok 10330, Thailand Email: karaked_ch@hotmail.com

studies $^{3}$ or into episodic viral wheeze (EVW) and multiple-trigger wheeze (MTW), categorized by The European Respiratory Society Task Force on Preschool Wheeze. ${ }^{4}$ Identification of these patterns of wheeze might allow the clinician to classify children during an office visit, which leads to effective treatment and follow up. ${ }^{5-7}$ However, the classifications of episodic and 
multiple-trigger wheeze might be unstable over time, with more than half of children switching to the other phenotype over the course of a year. ${ }^{8}$

In patients admitted for the first time with an acute wheezing episode, a commonly asked question from their parents is "Will my child wheeze again?". However, in Thailand, epidemiologic studies and long-term data are quite limited. A 5 -year prospective study at two tertiary hospitals in Khon Kaen revealed the recurrent wheezing of $61.8 \%$ in the first three years of follow-up, with the mean duration of $5.4 \pm 7.2$ months after the first episode of wheezing in children aged $1-24$ months. ${ }^{9}$

The current study focused on investigating the incidence of having a second episode of wheezing in preschool children, aged 6 months - 5 years, presenting with a first wheezing episode and identifying its associated factors during a one year follow-up period.

\section{Methods}

This observational prospective study was conducted at the inpatient Pediatric department of King Chulalongkorn Memorial Hospital from June 2014 to November 2015. This study was reviewed and approved by the human rights and ethics committee of the Faculty of Medicine, Chulalongkorn University, Thailand. Written informed consent was obtained from the parents of each patient. In this study, the term "recurrent wheezing" was defined as having a second wheezing episode requiring treatment with nebulized bronchodilator at any hospital within a 1-year follow-up.

\section{Participants and Procedure}

Patients were included in the study if they were admitted with a first episode of wheezing. Other criteria were age (6 months to 5 years old), nationality (Asian), and consent from parents. The subjects were then excluded if they had congenital or chronic illness (including chronic lung disease, bronchopulmonary dysplasia, cerebral palsy, congenital heart disease, congenital anomalies, structural airway malformation, primary immunodeficiency, gastroesophageal reflux disease, illness that requires steroid use) or clinical of sepsis or septic shock. Data concerning the age of the patients at the initial wheezing episode, sex, gestation age (preterm/term), breast -feeding duration, parental history of asthma, exposure to secondhand smoke, modified asthma predictive index(mAPI), comorbidity (allergic disease, including allergic rhinitis, atopic dermatitis, food allergy, cow's milk protein allergy, sensitization to aeroallergens) were obtained through an interview questionnaire. The severity of the acute episode was assessed using pulmonary index score. Data regarding the length of stay, treatment needed (high flow nasal cannula (HFNC)), and viral pathogen (RSV or Non-RSV) were collected from the medical records. Viral antigen detection was tested on subjects through nasopharyngeal swabs at the discretion of the primary doctor.

As shown in figure 1, at the beginning of the study, there were 97 patients recruited. The patients were followed up as an outpatient approximately one week after being discharged and subsequently received an active follow up by telephone 3-monthly with a structured interview questionnaire seeking information on recurrent wheezing within a one year period. Out of the 97 originally recruited, sixty-two patients completed the follow up. The reason for drop-out was due primarily to the inability to contact their parents who may have changed their telephone number without automatic update.

Amongst the 62 subjects completing the telephone followed up, eight subjects reported having a positive skin prick test. The medical records of these subjects were subsequently reviewed. The skin prick tests were done by allergists in the outpatient

\section{7 preschool children hospitalized with first episode of acute wheezing}

\section{Clinical evaluation and factors associated with recurrent wheezing collected}

\section{Discharged from hospital}

OPD follow-up approximately 1 week after wheezing episode and telephone follow-up 3-monthly until 1 year or until recurrent wheeze

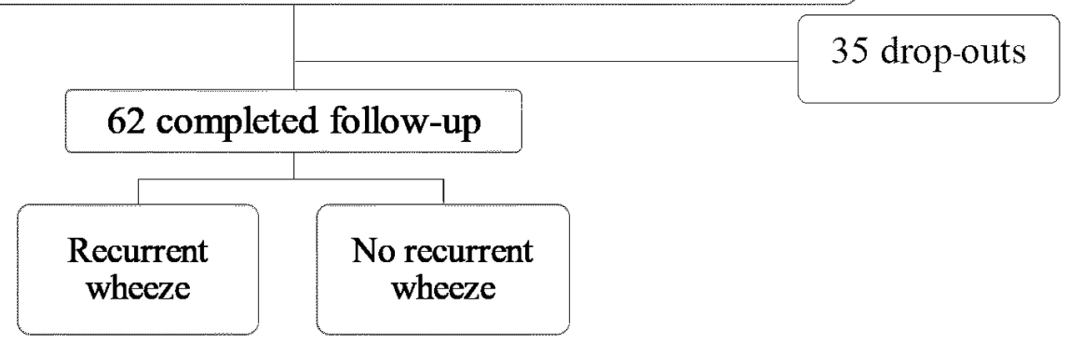

Figure 1. Patient disposition 
allergy clinic at King Chulalongkorn Memorial Hospital. A wheal of $3 \mathrm{~mm}$. or greater is considered a positive result. Types of food allergens are Cow's milk, Casein, Egg yolk, Egg white, Soy bean, Peanut, Wheat, and Shrimp. Whereas aeroallergens consists of; D.pteronyssinus, D.farinae, German cockroach, American cockroach, Cat, Dog, Mold (Aspergillus, Alternaria, Cladosporium, Penicillium), Bermuda grass, and Johnson grass. This covers most of the allergens common in Thai population. ${ }^{10}$

\section{Statistical Analysis}

Data were analyzed using Statistical Package for Social Sciences (SPSS) version 22. The descriptive analysis included calculating percentages and mean \pm SD for demographic variables. Logistic regression models were used to identify clinical variables associated with recurrent wheezing. Results from logistic models described by odds ratios and 95\%CI. $\mathrm{P}$-value $<0.05$ was considered to indicate statistical significance.

\section{Results}

\section{Demographic data}

The total of 97 patients with the age of 6 months to 5 years old were diagnosed with first episode wheezing. Thirty-five patients were excluded because of inaccessibility of the parents for follow-up. Their characteristics are presented in Table 1. There were no significant differences in clinical and demographic characteristics between the subjects and dropouts indicating that the sample population was representative of the root population of 97 patients.

Of the completed 62 patients, 28 patients (45.2\%) had recurrent wheezing while the remaining of 34 patients $(54.8 \%)$ did not have it. The mean lapse duration of recurrence was $4.7 \pm$ 3.7 months after the first episode.

Of the 62 patients included in the study, 31 (50\%) were male subjects. The mean age of the patients at admission was 23 months ( \pm 14.7 months). The weight and height of the patients are within the normal range for age. The entry points of study population varied, from visiting the emergency room (ER)/ outpatient department (OPD) without appointment $(88.7 \%$ being most of the case) to OPD with appointment and referred.

The record revealed that most of the subjects is of term, while $16.1 \%$ is of preterm. More than half $(56.5 \%)$ were breast fed for over 6 months. About $44 \%$ had been exposed to household cigarette smoke. The majority of the subjects $(88.7 \%)$ did not have co-morbid diseases, while only a few had atopic dermatitis (9.7\%) and food allergy (1.6\%).

\section{Factors associated with recurrent wheezing}

Table 2 shows the demographic and clinical characteristics of children with and without recurrent wheezing. The analysis revealed that demographic features and the severity of the wheezing episode; pulmonary index score, length of stay, and requirement of HFNC were not significant factors contributing to recurrent wheezing.

RSV infection was found positive in 21 subjects, eight $(28.6 \%)$ in the recurrent wheeze group comparing to 13 $(38.2 \%)$ in the other. There were 3 subjects tested positive for Rhinovirus, they all had recurrent wheezing. Four subjects were tested positive for other viruses each; Adenovirus, Bocavirus,
Table 1. Characteristics of study population and drop-outs

\begin{tabular}{|c|c|c|c|}
\hline Factors & $\begin{array}{l}\text { Subjects } \\
(n=62)\end{array}$ & $\begin{array}{c}\text { Drop-outs } \\
(\mathbf{n}=35)\end{array}$ & p-value \\
\hline \multicolumn{4}{|l|}{ Demographic data } \\
\hline $\begin{array}{l}\text { Age at } 1^{\text {st }} \text { wheezing } \\
\text { (months) }\end{array}$ & $23 \pm 14.7$ & $23.71 \pm 14.05$ & 0.811 \\
\hline Male sex & $31(50 \%)$ & $17(48.6 \%)$ & 0.892 \\
\hline Preterm & $10(16.1 \%)$ & $2(6.3 \%)$ & 0.174 \\
\hline $\begin{array}{l}\text { Exposure to cigarette } \\
\text { smoke }\end{array}$ & $27(44.3 \%)$ & $2(40 \%)$ & 0.854 \\
\hline \multicolumn{4}{|l|}{ Allergy-related history } \\
\hline Parental asthma & $7(11.3 \%)$ & $3(17.6 \%)$ & 0.360 \\
\hline Atopic dermatitis & $6(9.7 \%)$ & $1(2.9 \%)$ & 0.213 \\
\hline $\begin{array}{l}\text { Allergic sensitization to } \\
\text { aeroallergen }\end{array}$ & $5(8.1 \%)$ & $0(0 \%)$ & 0.085 \\
\hline Eosinophilia $>4 \%$ & $3(4.8 \%)$ & $0(0 \%)$ & 0.186 \\
\hline $\begin{array}{l}\text { Allergic sensitization } \\
\text { to food }\end{array}$ & $3(4.8 \%)$ & $0(0 \%)$ & 0.186 \\
\hline Allergic rhinitis & $2(3.2 \%)$ & $1(2.9 \%)$ & 0.920 \\
\hline Positive mAPI & $13(23.2 \%)$ & $4(11.4 \%)$ & 0.161 \\
\hline \multicolumn{4}{|l|}{ Severity } \\
\hline PIS before treatment & $5.76 \pm 2.01$ & $5.95 \pm 1.67$ & 0.703 \\
\hline Required HFNC & $7(13.7 \%)$ & $2(5.7 \%)$ & 0.233 \\
\hline Length of stay (days) & $3.69 \pm 2.85$ & $3.97 \pm 2.13$ & 0.617 \\
\hline RSV positive & $21(33.9 \%)$ & $12(34.3 \%)$ & 0.967 \\
\hline
\end{tabular}

Values presented as frequency (\%), Mean \pm SD. and Odds ratio (95\%; Confidence interval). P-value corresponds to Logistic regression analysis HFNC, high flow nasal cannula; mAPI, modified asthma predictive index; PIS, pulmonary index score; RSV, respiratory syncytial virus

Human metapneumovirus, and Influenza virus. These subjects did not have recurrent wheezing. However, some of the subjects were tested with RSV rapid test only, hence did not undergo other viral antigen detection. No significant association between respiratory viruses and recurrent wheezing was demonstrated in this study.

During the follow-up period, eight out of 62 subjects was found to have a positive skin prick test. In one subject, the skin prick test was done after having the wheezing episode, while the other 7 subjects underwent a skin prick test after having a second attack. Five were positive to aeroallergens, two were positive to food allergens, and 1 was positive to both. From the initial interview, three subjects were suspected to have food allergies. They all underwent a skin prick test for food allergens, and the tests were positive. Allergic sensitization to aeroallergen was a factor identified as being of significance (odds ratio 2.48, 95\%CI 1.81-3.4) and allergic sensitization to food also contributes to the risk of recurrent wheezing (odds ratio 2.36 , 95\% CI 1.75-3.18). While, parental asthma, atopic dermatitis, eosinophilia $>4 \%$, allergic rhinitis, and a positive 
Table 2. Demographic and clinical characteristics of children with and without recurrent wheezing

\begin{tabular}{|c|c|c|c|c|}
\hline Factors & $\begin{array}{c}\text { Recurrent } \\
\text { wheeze }(n=28)\end{array}$ & $\begin{array}{c}\text { No recurrent } \\
\text { wheeze }(n=34)\end{array}$ & OR $(95 \% \mathrm{CI})$ & p-value \\
\hline \multicolumn{5}{|l|}{ Demographic data } \\
\hline Age at $1^{\text {st }}$ wheezing (months) & $20.21 \pm 13.06$ & $25.29 \pm 14.63$ & $0.97(0.94,1.01)$ & 0.161 \\
\hline Male sex & $16(57.1 \%)$ & $15(44.1 \%)$ & $1.33(0.76,2.33)$ & 0.444 \\
\hline Preterm & $6(21.4 \%)$ & $4(11.8 \%)$ & $1.42(0.78,2.58)$ & 0.326 \\
\hline Breast fed $>6$ months & $14(50 \%)$ & $21(61.8 \%)$ & $0.77(0.45,1.33)$ & 0.443 \\
\hline Exposure to cigarette smoke & $10(35.7 \%)$ & $17(51.5 \%)$ & $0.72(0.4,1.3)$ & 0.31 \\
\hline \multicolumn{5}{|l|}{ Allergy-related history } \\
\hline Parental asthma & $1(3.6 \%)$ & $5(14.7 \%)$ & $0.35(0.06,2.11)$ & 0.209 \\
\hline Atopic dermatitis & $3(10.7 \%)$ & $3(8.8 \%)$ & $1.12(0.48,2.62)$ & 1 \\
\hline Allergic sensitization to aeroallergen & $5(17.9 \%)$ & $0(0 \%)$ & $2.48(1.81,3.4)$ & $0.015^{*}$ \\
\hline Eosinophilia > 4\% & $1(3.6 \%)$ & $2(5.9 \%)$ & $0.73(0.14,3.7)$ & 1 \\
\hline Allergic sensitization to food & $3(10.7 \%)$ & $0(0 \%)$ & $2.36(1.75,3.18)$ & 0.087 \\
\hline Allergic rhinitis & $1(3.6 \%)$ & $1(2.9 \%)$ & $1.11(0.27,4.57)$ & 1 \\
\hline Positive mAPI & $8(28.6 \%)$ & $5(17.9 \%)$ & $1.51(0.87,2.6)$ & 0.22 \\
\hline \multicolumn{5}{|l|}{ Severity } \\
\hline PIS before treatment & $5.7 \pm 1.59$ & $5.81 \pm 2.34$ & $0.97(0.75,1.26)$ & 0.845 \\
\hline Required HFNC & $4(15.4 \%)$ & $3(12 \%)$ & $1.31(0.64,2.66)$ & 0.691 \\
\hline Length of stay (days) & $3 \pm 1.47$ & $4.26 \pm 3.54$ & $0.77(0.56,1.05)$ & 0.095 \\
\hline RSV positive & $8(28.6 \%)$ & $13(38.2 \%)$ & $0.78(0.42,1.46)$ & 0.59 \\
\hline
\end{tabular}

Values presented as frequency (\%), Mean \pm SD. and Odds ratio (95\%; Confidence interval). P-value corresponds to Logistic regression analysis HFNC, high flow nasal cannula; mAPI, modified asthma predictive index; PIS, pulmonary index score; RSV, respiratory syncytial virus

mAPI were not significant factors influencing the recurrence of wheezing.

\section{Discussion}

Several birth cohort studies have revealed the natural history of wheezing in preschool children. ${ }^{11-13}$ In 2008, reclassification of preschool wheezing to EVW and MTW was recommended. ${ }^{4}$ This study attempts to investigate the incidence of a second episode wheezing after only the first episode, which all of the subjects had a history of preceding viral upper respiratory tract infection. The incidence of recurrent wheezing of $45 \%$ found in this study corresponds with the results of prospective studies reported by Schultz et al. in $2010^{8}$ and Kappelle et al. in 2012, ${ }^{14}$ and in line with the retrospective study of Topal et al. in $2013,{ }^{15}$ as well as the results of a study in Thailand carried out by Teeratakulpisarn et al. in $2014 .^{9}$

Schultz et al. ${ }^{8}$ studied 38 cases of EVW for one year and found that $65.8 \%$ had recurrent wheezing. Which the phenotype classification remained as EVW in $31.6 \%$ of the cases, $34.2 \%$ changed to MTW, and the remaining 34.2\% recovered. Kappelle et al., ${ }^{14}$ who studied 78 patients with severe EVW for 3.9 years, also reported that $66.7 \%$ of the patients had recurrent wheezing, while $33.3 \%$ recovered. The retrospective study of 236 cases by Topal et al. 2013 on short-term changes in phenotype of EVW and MTW concluded that EVW phenotype is not stable and may change over a short-term follow-up period. ${ }^{15}$

A positive mAPI for major criteria, and anti-inflammatory treatment at the time of diagnosis were identified as predictors of persistence of wheeze in preschool children with EVW by Topal et al., ${ }^{15}$ this present study did not find these elements to be of statistical significance.

Previous studies have shown the benefit of the mAPI in predicting asthma development in patients having 4 or more episodes of wheezing. Lowering the number of wheezing episodes to 2 (m2API) lowered the predictive value after a positive test. ${ }^{16}$ This study used the mAPI to evaluate patients with only a first wheezing episode, and found no significant association between a positive mAPI and recurrent wheezing. Therefore, it could be implied that in patients with a first episode of wheezing, a positive mAPI does not indicate a higher risk of recurrence.

The severity of symptoms in this study, assessed by the Pulmonary Index Score, length of stay, and the requirement of HFNC was not found to have any differences between both groups. This differs from the study of Bessa et al. 2014, ${ }^{17}$ which found that recurrent wheezers had more severe symptoms, nocturnal symptoms, and visits to emergency rooms and hospitalizations for wheezing and pneumonia, when compared 
to infants with occasional wheezing. However, all the subjects in this study were hospitalized. This accounts for already having severe symptoms, which might be the reason for the insignificant differences of these factors between both groups. As for the factor of having an RSV infection, no association with recurrent wheezing was found, similar to previous studies. ${ }^{18,19}$

The present study identified one risk factor for recurrent wheezing in preschool children with first episode wheezing: allergic sensitization to aeroallergen. Allergic sensitization to food also contributes to the risk of recurrent wheezing, although it was not statistically significant. These results are similar to the Prevention of Asthma in Kids (PEAK) trial in 2004. ${ }^{20}$ However, it is not a common practice in Thailand to perform skin prick tests in patients with only a first wheezing episode. It is usually done in cases of recurrent wheezing, which asthma is suspected. Although there was a trend for family history of asthma to be associated with recurrent wheezing, it was not conclusive in this study that it is a risk factor for recurrent wheezing. Other factors previously found to have significant association with recurrent wheezing are blood eosinophilia, atopic dermatitis, and a history of earlier episodes of wheezing in infancy. ${ }^{21}$ These factors were not found to have an association with recurrent wheezing in this study.

The advantage of this study is that it is a prospective study. This justifies the ability to identify associated factors which are considered as risks for recurrent wheezing. However, the present study is considered to have the following limitations.

First, the study sample size was relatively small, limiting the ability to identify associated factors of recurrent wheezing during the one-year follow-up period. This is because this study only includes children admitted with first episode wheezing and excludes patients with already recurrent wheezing (either from the hospital records or the history suggested by their parents). The study population was representative of the initial population of 97 children positively identified as having a first episode wheezing (Table 1) in terms of age, gender, and history of allergic diseases. Further studies in larger prospective hospital-based cohorts of patients presenting with first episode wheezing are needed to confirm the results of the present study.

Secondly, the duration of follow-up was until the patient had a second episode wheezing, with a maximum duration of one-year period. Although recurrent wheezing was reported to occur mostly within the first year, with a mean duration 5.5 \pm 7.2 months after the first episode, ${ }^{9}$ which bears a resemblance to this study of $4.7 \pm 3.7$ months, other long-term follow-up cohort studies have shown that a number of patients had recurrent wheezing later in life and were diagnosed with asthma beyond the preschool age. ${ }^{22-24}$ By extending the duration of the follow -up, the phenotypes of wheezing could be classified and the natural history of patients presenting with first episode wheezing could be more clarified.

A third limitation is that respiratory virus detection during episodes of wheezing was not performed in every subject. Previous studies have looked in to respiratory viruses in preschool wheeze and suggested that rhinovirus and respiratory syncytial virus may have impact on increasing the likelihood of persistent asthma. ${ }^{9,25,26}$ However, viral testing is not necessary in children presenting with wheezing and is not recommended in clinical guidelines for preschool wheeze. ${ }^{4}$ Therefore, data collected on respiratory viruses in this study was limited, and so no association between respiratory viruses and recurrent wheezing could be demonstrated.

The final limitation is that this study was conducted in a single center, which may limit the generalizability of the findings. Nonetheless, King Chulalongkorn Memorial Hospital is a tertiary hospital located at the city center of Bangkok. Hence, a number of patients visit the emergency room and the out -patient department each day, including patients referred from other hospitals. Therefore, it is believed that the subjects in this study are a representative of preschool children with first episode wheezing in a tertiary care center.

In conclusion, the incidence of recurrent wheezing in preschool children, age 6 months -5 years, presenting with first wheezing is $45 \%$ which is of significance, with mean lapse duration of recurrence from the first episode of $4.7 \pm 3.7$ months. It remains a challenge for the clinicians to differentiate children with transient symptoms from children who will have recurrent wheezing. Having an allergic sensitization to aeroallergen could increase their risks. It is recommended to evaluate and follow up preschool children with first episode wheezing within the first year of their attack, especially patients with the risk factor above, so that clinicians could be able to early detect cases likely to develop recurrence

\section{Acknowledgement}

The authors gratefully acknowledge the cooperation of the children and parents who have participated in this study. Valued contributions of the medical record office, King Chulalongkorn Memorial Hospital and the Thailand Research Fund (IRG5780015) are also recognized.

\section{References}

1. Bisgaard H, Szefler S. Prevalence of asthma-like symptoms in young children. Pediatr Pulmonol. 2007;42(8):723-8.

2. Martinez FD, Wright AL, Taussig LM, Holberg CJ, Halonen M, Morgan WJ. Asthma and wheezing in the first six years of life. The Group Health Medical Associates. N Engl J Med. 1995;332(3):133-8.

3. Taussig LM, Wright AL, Holberg CJ, Halonen M, Morgan WJ, Martinez FD. Tucson Children's Respiratory Study: 1980 to present. J Allergy Clin Immunol. 2003;111(4):661-75; quiz 76.

4. Brand PL, Baraldi E, Bisgaard H, Boner AL, Castro-Rodriguez JA, Custovic A, et al. Definition, assessment and treatment of wheezing disorders in preschool children: an evidence-based approach. Eur Respir J. 2008;32(4):1096-110.

5. McKean M, Ducharme F. Inhaled steroids for episodic viral wheeze of childhood. Cochrane Database Syst Rev. 2000(2):CD001107.

6. Kaditis AG, Winnie G, Syrogiannopoulos GA. Anti-inflammatory pharmacotherapy for wheezing in preschool children. Pediatr Pulmonol. 2007;42(5):407-20.

7. Saglani S, Payne DN, Zhu J, Wang Z, Nicholson AG, Bush A, et al. Early detection of airway wall remodeling and eosinophilic inflammation in preschool wheezers. Am J Respir Crit Care Med. 2007;176(9):858-64.

8. Schultz A, Devadason SG, Savenije OE, Sly PD, Le Souef PN, Brand PL. The transient value of classifying preschool wheeze into episodic viral wheeze and multiple trigger wheeze. Acta Paediatr. 2010;99(1):56-60.

9. Teeratakulpisarn J, Pientong C, Ekalaksananan T, Ruangsiripiyakul H, Uppala R. Rhinovirus infection in children hospitalized with acute bronchiolitis and its impact on subsequent wheezing or asthma: a comparison of etiologies. Asian Pac J Allergy Immunol. 2014;32(3):226-34.

10. Tham EH, Lee AJ, Bever HV. Aeroallergen sensitization and allergic disease phenotypes in Asia. Asian Pac J Allergy Immunol. 2016;34(3):181-9.

11. Castro-Rodriguez JA, Holberg CJ, Wright AL, Martinez FD. A clinical index to define risk of asthma in young children with recurrent wheezing. Am J Respir Crit Care Med. 2000;162(4 Pt 1):1403-6. 
APJAI

12. Kurukulaaratchy RJ, Matthews S, Holgate ST, Arshad SH. Predicting persistent disease among children who wheeze during early life. Eur Respir J. 2003;22(5):767-71.

13. Caudri D, Wijga A, CM AS, Hoekstra M, Postma DS, Koppelman GH, et al. Predicting the long-term prognosis of children with symptoms suggestive of asthma at preschool age. J Allergy Clin Immunol. 2009;124(5):903-10 e1-7.

14. Kappelle L, Brand PL. Severe episodic viral wheeze in preschool children: High risk of asthma at age 5-10 years. Eur J Pediatr. 2012;171(6):947-54

15. Topal E, Bakirtas A, Yilmaz O, Ertoy Karagol IH, Arga M, Demirsoy MS, et al. Short-term follow-up of episodic wheeze and predictive factors for persistent wheeze. Allergy Asthma Proc. 2013;34(6):e42-6.

16. Chang TS, Lemanske RF Jr, Guilbert TW, Gern JE, Coen MH, Evans MD, et al. Evaluation of the modified asthma predictive index in high-risk preschool children. J Allergy Clin Immunol Pract. 2013;1(2):152-6.

17. Bessa OA, Leite AJ, Sole D, Mallol J. Prevalence and risk factors associated with wheezing in the first year of life. J Pediatr (Rio J). 2014;90(2):190-6.

18. Kneyber MCJ, Steyerberg EW, de Groot R, Moll HA. Long-term effects of respiratory syncytial virus (RSV) bronchiolitis in infants and young children: a quantitative review. Acta Paediatr. 2000;89(6):654-60.

19. Valkonen H, Waris M, Ruohola A, Ruuskanen O, Heikkinen T. Recurrent wheezing after respiratory syncytial virus or non-respiratory syncytial virus bronchiolitis in infancy: a 3-year follow-up. Allergy. 2009;64(9):1359-65.
20. Guilbert TW, Morgan WJ, Zeiger RS, Bacharier LB, Boehmer SJ, Krawiec $\mathrm{M}$, et al. Atopic characteristics of children with recurrent wheezing at high risk for the development of childhood asthma. J Allergy Clin Immunol. 2004;114(6):1282-7.

21. Kotaniemi-Syrjanen A, Reijonen TM, Korhonen K, Korppi M. Wheezing requiring hospitalization in early childhood: predictive factors for asthma in a six-year follow-up. Pediatr Allergy Immunol. 2002;13(6):418-25.

22. Klinnert MD, Nelson HS, Price MR, Adinoff AD, Leung DY, Mrazek DA. Onset and persistence of childhood asthma: predictors from infancy. Pediatrics. 2001;108(4):E69.

23. To T, Gershon A, Wang C, Dell S, Cicutto L. Persistence and remission in childhood asthma: a population-based asthma birth cohort study. Arch Pediatr Adolesc Med. 2007;161(12):1197-204.

24. Lasso-Pirot A, Delgado-Villalta S, Spanier AJ. Early childhood wheezers: identifying asthma in later life. J Asthma Allergy. 2015;8:63-73.

25. Jackson DJ, Gangnon RE, Evans MD, Roberg KA, Anderson EL, Pappas $\mathrm{TE}$, et al. Wheezing rhinovirus illnesses in early life predict asthma development in high-risk children. Am J Respir Crit Care Med. 2008;178(7):667-72.

26. Garcia-Garcia ML, Calvo C, Falcon A, Pozo F, Perez-Brena P, De Cea JM, et al. Role of emerging respiratory viruses in children with severe acute wheezing. Pediatr Pulmonol. 2010;45(6):585-91. 